\title{
Humbert de Montmoret, Germain de Brie, Pierre Choque, L'incendie de la Cordelière
}

\section{Filippo Fonio}

\section{(2) OpenEdition}

1 Journals

\section{Edizione digitale}

URL: https://journals.openedition.org/studifrancesi/26082

DOI: $10.4000 /$ studifrancesi.26082

ISSN: 2421-5856

\section{Editore}

Rosenberg \& Sellier

\section{Edizione cartacea}

Data di pubblicazione: 1 avril 2007

Paginazione: 160-161

ISSN: 0039-2944

\section{Notizia bibliografica digitale}

Filippo Fonio, «Humbert de Montmoret, Germain de Brie, Pierre Choque, L'incendie de la Cordelière»,

Studi Francesi [Online], 151 (LI | I) | 2007, online dal 30 novembre 2015, consultato il 23 novembre 2021. URL: http://journals.openedition.org/studifrancesi/26082 ; DOI: https://doi.org/10.4000/ studifrancesi.26082

Questo documento è stato generato automaticamente il 23 novembre 2021.

\section{(c)}

Studi Francesi è distribuita con Licenza Creative Commons Attribuzione - Non commerciale - Non opere derivate 4.0 Internazionale. 


\title{
Humbert de Montmoret, Germain de Brie, Pierre Choque, L'incendie de la Cordelière
}

\author{
Filippo Fonio
}

\section{NOTIZIA}

HUMBERT DE MONTMORET, GERMAIN DE BRIE, PIERRE CHOQUE, L'incendie de la Cordelière. Textes présentés et traduits par Sandra PRovinI, avec une préface de Perrine GALAND-HALLYN, La Rochelle, Rumeur des Ages, 2004, pp. 146.

1 Le tre opere qui raccolte sono commemorazioni in versi della battaglia navale di La Cordelière, svoltasi il 10 agosto del 1512 al largo di Brest tra la flotta francese e quella inglese, e conclusasi con la perdita delle due ammiraglie.

2 Si tratta dell'Herveis di Humbert de Montmoret e della Chordigerae navis conflagratio di Germain de Brie, poeti neolatini attivi alla corte di Louis XII, qui tradotte dalla curatrice, e della versione francese in décasyllabes dell'epillio di Brie, a firma di Pierre Choque, protetto di Anne de Bretagne. Queste opere possono essere annoverate fra $i$ primi tentativi epici del Rinascimento francese, mossi dall'esigenza, comune anche alla Pléiade, di dare alla Francia un'epica. La più fortunata fra le tre è probabilmente quella di Brie, fra l'altro al centro di una polemica con Thomas More, protrattasi dal 1519 al 1521. Edita da Josse Bade nel 1513, la Chordigerae navis conflagratio è già stata oggetto di un'edizione critica nel 1980. L'Herveis conosce una sola stampa (da Hémon Le Fevre, sempre nel 1513), mentre la traduzione di Choque è rimasta inedita fino al 1844.

3 Una delle questioni fondamentali affrontate dalla studiosa nell'introduzione è quella dell'appartenenza di genere delle tre opere. Parlare infatti di epica breve o di epillio rischia di essere riduttivo, sebbene la celebrazione del capitano bretone Hervé de Portzmoguer assuma forme specificamente epiche, e l'Eneide resti un modello comune ai poeti. Nondimeno, la forte presenza autoriale costituisce un'importante deroga ai 
crismi dell'epica, come pure la brevità e l'argomento contemporaneo, prossimo alla cronaca. Inoltre, l'interferenza di altri modelli come la silva (staziana, ma anche quella umanistica di Poliziano, importante in particolare sul piano della poetica) o l'epica extracanonica di Ovidio, Lucano e Claudiano arricchiscono la prospettiva imitativa delle tre opere, per le quali è piuttosto attivo il principio quintilianeo dell'aemulatio, dell'imitazione selettiva, mediato da Poliziano, dall'umanesimo parigino $e$ in particolare dalla Poetica di Dubuis (specie nel caso di Montmoret) e da Girolamo Aleandro, fra l'altro autore dell'epistola prefatoria alla Chordigerae navis conflagratio. Si può dunque parlare in maniera più circostanziata di silve eroiche dotate di tratti epici.

4 I tre poeti condividono il medesimo substrato culturale, frequentano gli stessi ambienti, e probabilmente Brie conosceva l'Herveis di Montmoret (a meno che non si possa individuare una fonte comune). Uniscono erudizione e sperimentalismo, indignatio per la parte avversa e admiratio per il valoroso condottiero morto in servizio, patetico e sublime, con l'intenzione di movere il lettore. Hervé presenta le caratteristiche dell'eroe antico e del cavaliere medievale, anche se in quest'epica della guerra moderna lo spazio riservato all'individualismo appare di molto ridimensionato. Mentre nell'Herveis la fine dell'eroe è assimilata a un suicidio stoico, Brie accentua la componente religiosa dell'impresa come veicolo del sublime, e la morte per la patria viene vista sotto forma di un martirio per la fede. La traduzione di Choque insiste invece sui dettagli storici e militari, a discapito del meraviglioso, ferma restando l'importanza dell'elemento sacro e quasi di una mistica della guerra. 